\title{
Comparison of Compressive Strength and Setting Time of Four Experimental Nanohybrid Mineral Trioxide Aggregates and Angelus Mineral Trioxide Aggregate
}

\author{
${ }^{1}$ Kasra Tabari, ${ }^{2}$ Mahdi Rahbar, ${ }^{3}$ Leila Safyari, ${ }^{4}$ Hossein Safarvand
}

\begin{abstract}
Aim: The present study was carried out with the objective of comparing the compressive strength and setting time of four experimental nanohybrid mineral trioxide aggregates (MTAs) and angelus MTA.
\end{abstract}

Materials and methods: In this research, four experimental formulations of nanohybrid MTA (groups are with the base of Portland cement, containing nanoparticles of zirconia, aluminum oxide, titanium, nanosilica, and gypsum and bismuth trioxide) and angelus MTA were compared. Powder and water were mixed with the ratio determined by a factory for angelus MTA and were mixed at a ratio of 3:1 in experimental samples until the consistency of putty was reached. These were then placed in stainless steel cylinder generators, with a diameter of $4 \mathrm{~mm}$ and a height of $6 \mathrm{~mm}$, for testing compressive strength, and in generators with a diameter of $10 \mathrm{~mm}$ and height of $2 \mathrm{~mm}$ to test setting time. The samples prepared were tested after 24 hours and a month using a strength-testing machine. A $135 \mathrm{G}$ needle was used to test the initial setting time in the prepared samples, and a $456.5 \mathrm{G}$ needle was used to test the final setting time. In the end, data were analyzed using Statistical Package for the Social Sciences (SPSS) software.

Results: Experimental nanohybrid MTA P significantly showed the minimum setting time and experimental nanohybrid MTA $Q$ showed the maximum setting time in 30 days $(p<0.05)$. Angelus MTA had greater compressive strength than the experimental materials in 24 hours.

Conclusion: Experimental MTAs showed less setting time compared with the angelus MTA. Addition of nanoparticles in the $Q$ group significantly affected the compressive strength of MTA. Compressive strength significantly increased over time in all groups.

Clinical significance: Considering that experimental MTAs showed less setting time compared with the commercial type, experimental MTAs can be deployed in clinical usage.

${ }^{1}$ Department of Operative and Esthetic Dentistry, Dental Research Center, Faculty of Dentistry, Shahid Beheshti University of Medical Sciences, Tehran, Islamic Republic of Iran

${ }^{2-4}$ Department of Operative and Esthetic Dentistry, Faculty of Dentistry, Tabriz University of Medical Science, Tabriz, Islamic Republic of Iran

Corresponding Author: Leila Safyari, Department of Operative and Esthetic Dentistry, Faculty of Dentistry, Tabriz University of Medical Science, Tabriz, Islamic Republic of Iran, e-mail: leilasafyari@gmail.com
Keywords: Compressive strength, Mineral trioxide aggregate, Nanoparticles, Setting time.

How to cite this article: Tabari K, Rahbar M, Safyari L, Safarvand $\mathrm{H}$. Comparison of Compressive Strength and Setting Time of Four Experimental Nanohybrid Mineral Trioxide Aggregates and Angelus Mineral Trioxide Aggregate. World J Dent 2017;8(5):386-392.

Source of support: Nil

Conflict of interest: None

\section{INTRODUCTION}

The use of MTA in dentistry as a material for sealing the ends of the roots began after retrograde surgeries. Nowadays, these materials have a variety of applications, such as closing perforations on pulp chamber floor, ${ }^{1}$ repairing furcation perforations ${ }^{2}$ and creating apical barrier, ${ }^{3}$ coating material after pulpotomy in permanent teeth ${ }^{4}$ and primary teeth, ${ }^{5}$ filling the roots of primary teeth ${ }^{6}$ and undeveloped permanent teeth ${ }^{7}$ and developed teeth, ${ }^{8}$ apexification of undeveloped teeth with necrosis pulp, ${ }^{9}$ and sealer on the tooth root. ${ }^{10}$ Improving MTA's mechanical and physical properties will be among the priorities, given the sensitivity of using MTA, especially in maintaining pulp vitality and creation of apical barrier. Nowadays, different restorative materials and root fillers are available, such as amalgam, resin composite, ethoxybenzoic acid cement, glass ionomer cement, gutta-percha, and zinc oxide-eugenol cement. Their significant disadvantages, however, are microleakage, toxicity, and susceptibility to moisture. ${ }^{11}$

The MTA is a filling material with high sealing properties and high biocompatibility ${ }^{11}$ but has a low early compressive strength. Its strength in the first 24 hours is $40 \mathrm{MPa}$, which reaches $67 \mathrm{MPa}$ after 3 weeks, and is significantly less than amalgam (compressive strength of amalgam is $311 \mathrm{MPa}){ }^{12}$ Its setting time is higher than amalgam, super ethoxybenzoic acid, and intermediate restorative material, and is about 2 hours and 45 minutes. Longer setting time leads to having more contaminated material in the oral environment and restorative material being placed on it in pulp capping with less security. In addition, the time that the cement is washed in the mouth will increase. ${ }^{13}$ Thus, unfortunately, its use in dentistry is limited due to the long setting time and low compressive strength compared with other dental 
Comparison of Compressive Strength and Setting Time of Four Experimental Nanohybrid MTAs

Table 1: Composition of studied experimental MTAs

\begin{tabular}{llllllll}
\hline $\begin{array}{l}\text { Experimental } \\
\text { group }\end{array}$ & & & Nano Aluminum & & & \\
Portland cement & Nano Zirconia & Oxide & Nano Titanium & Nano Silis & Bismuth Oxide & Gypsum \\
\hline S & $\checkmark$ & $\checkmark$ & $\checkmark$ & $\checkmark$ & $\checkmark$ & $\checkmark$ & $\checkmark$ \\
P & $\checkmark$ & $\checkmark$ & $\checkmark$ & $\checkmark$ & $\checkmark$ & $\checkmark$ & - \\
R & $\checkmark$ & $\checkmark$ & - & $\checkmark$ & $\checkmark$ & $\checkmark$ & - \\
\hline
\end{tabular}

materials. ${ }^{12}$ Structure and chemical composition of MTA make working with this material very difficult in the dental office. ${ }^{14}$ Several studies ${ }^{15-19}$ have shown that the use of both white and gray MTA causes tooth discoloration due to the release of metal ions; this limits the use of MTA in the treatment of perforation pulp capping and pulpotomy, especially in esthetic areas. ${ }^{15}$

Attention has been paid to applications of nanotechnology in the field of cement along with the development of this science in various industries. Various oxides on the nanoscale have been used to improve physical and mechanical properties and durability of cements, ${ }^{17}$ such as silica nano-oxide, ${ }^{18}$ titanium, and aluminum oxide. Using these particles can improve the properties of cement due to their surface area, high reactivity, and ability to enable functionality. ${ }^{19}$ The present study aims to assess the effect of addition of nano- $\mathrm{TiO}_{2}$, nano-zirconia, nano- $\mathrm{SiO}_{2}$, and nano- $\mathrm{Al}_{2} \mathrm{O}_{3}$ to compressive strength and setting time of four experimental formulations of MTA and angelus MTA.

\section{MATERIALS AND METHODS}

The MTA samples studied are based on International Organization for Standardization (ISO) guidelines. A total of 115 samples were prepared, considering the number of samples examined in the research. A total of 100 samples were considered for compressive strength testing (10 samples from each group and two periods), and 15 samples were considered to test setting time (three samples in each group). Selection and preparation of samples were carried out nonrandomly and easily. The sample size to evaluate the compressive strength test was a diameter of $4 \mathrm{~mm}$ and thickness of $6 \mathrm{~mm}$, and the sample size to evaluate the setting time was a diameter of $10 \mathrm{~mm}$ and thickness of $2 \mathrm{~mm}$. This was an in vitro experimental study done on experimental nanohybrid MTA and angelus MTA samples. The experimental groups are with the base of Portland cement, containing nanoparticles of zirconia, aluminum oxide, titanium, nanosilica, and gypsum and bismuth trioxide, with differences in the four groups (Table 1).

\section{Compressive Strength}

Powder and water were mixed in commercial samples at a weight ratio (with the help of Acculab digital scale with an accuracy of $0.0001 \mathrm{gm}$ ) set by the factory (3:1), to achieve sandy gravel consistency, and were mixed in experimental samples until putty consistency was achieved. These were then placed in generators: internal dimensions with a diameter of $4 \pm 0.1 \mathrm{~mm}$ and thickness of $6 \pm 0.1 \mathrm{~mm}$, made of stainless steel (ISO 9917-1). Ten samples were prepared for each material group. The samples prepared were taken out of the generator after a 3-minute initial setting time. Samples with cracks, bubbles, or surface irregularities were excluded from the study. Normal and perfect samples were stored at a temperature of $37^{\circ} \mathrm{C}$ and humidity of $95 \% \pm 5 \%$ and were tested after 24 hours and a month, using a Universal Testing Machine (Zwick/Roel Z020/Zwick GmbH and Co. KG, Germany) (Fig. 1) at a speed of $0.05 \mathrm{~mm} /$ minute. $^{20}$

\section{Setting Time}

According to ISO 6876 2012, mixed samples were placed inside circle generators with a diameter of $10 \mathrm{~mm}$ and thickness of $2 \mathrm{~mm}$; three samples were prepared for each group of material. ${ }^{20}$ After mixing the materials in accordance with the manufacturer's instructions, initially the timer (Akai timer China stopwatch with an accuracy of one-hundredth of a second) was set to zero, and the timer was turned on



Figs 1A to $C$ : (A) Samples made from each group to measure compressive strength test; $(B)$ generator made of stainless steel that was used to test compressive strength; and (C) universal testing machine (Zwick Z020, Germany) 
Table 2: Mean and SD of compressive strength of commercial MTA and four types of experimental MTAs after 24 hours and 30 days

\begin{tabular}{lllllll}
\hline Time & $N$ & Angelus & $P$ & $Q$ & $R$ & $S$ \\
\hline 24 hours & 50 & $30.17 \pm 1.35^{*}$ & $13.96 \pm 0.87$ & $26.39 \pm 2.51$ & $26.26 \pm 0.99$ & $18.97 \pm 1.19$ \\
30 days & 50 & $65.03 \pm 3.75$ & $64.73 \pm 3.02$ & $90.51 \pm 3.97$ & $76.14 \pm 1.61$ & $63.91 \pm 3.01$ \\
\hline
\end{tabular}

${ }^{*}$ Mean \pm SD; SD: Standard deviation

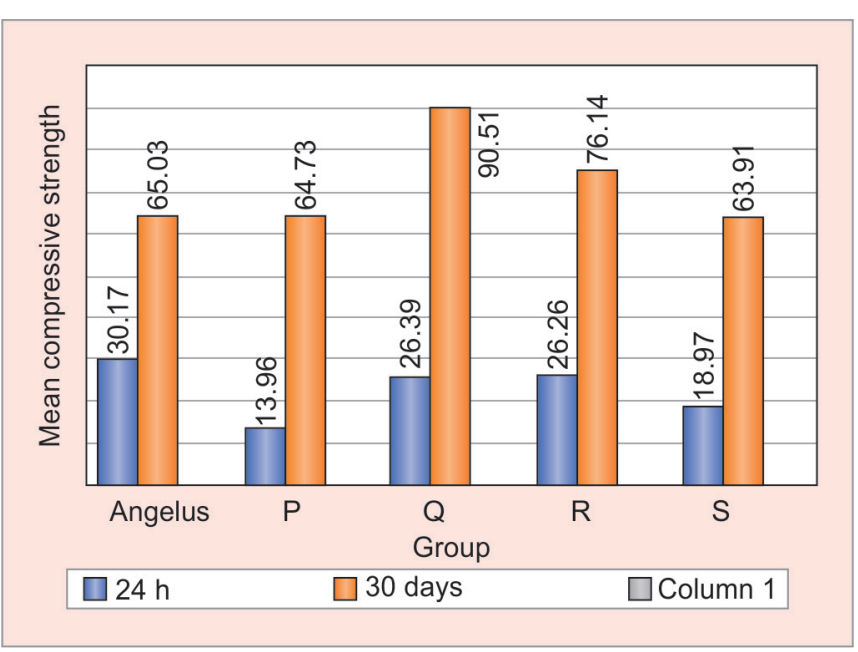

Graph 1: The average compressive strength of commercial MTAs and four types of experimental MTAs after 24 hours and 30 days

after mixing. The surface of the sample was smoothed by a clean metal spatula after pressing it inside the generator. The head of the device was placed on a horizontal surface of material at intervals of 30 seconds for 5 seconds. ${ }^{20}$ This device has two needles-the initial needle has a diameter of $2.12 \mathrm{~mm}$ and a weight of $113.4 \mathrm{gm}$, whereas the other needle has a diameter of $1.06 \mathrm{~mm}$ and a weight of 453.6 $\mathrm{gm}$. The effect of needle dents shows the lack of hardening of the material examined. Setting time was considered from the time of mixing the material until the time when no cracks could be created on the surface of the sample.

The collected data were analyzed using SPSS version 16. Normality of the data distribution $(p=0.307)$ was confirmed using Kolmogorov-Smirnov test. As a result, parametric statistical methods have been used for making comparisons. A paired t-test was used to compare the results of the compressive strength as well as the initial and final setting times in each group. Repeated measures analysis of variance was used to compare compressive strength in groups with each other and at different times, as well as to compare the setting time in groups with each other with respect to the initial and final times; $p<0.05$ was considered statistically significant in this study.

\section{RESULTS}

\section{Findings related to Compressive Strength}

The average compressive strengths of commercial MTA and four types of experimental MTA after 24 hours and 30 days are shown in Table 2 .

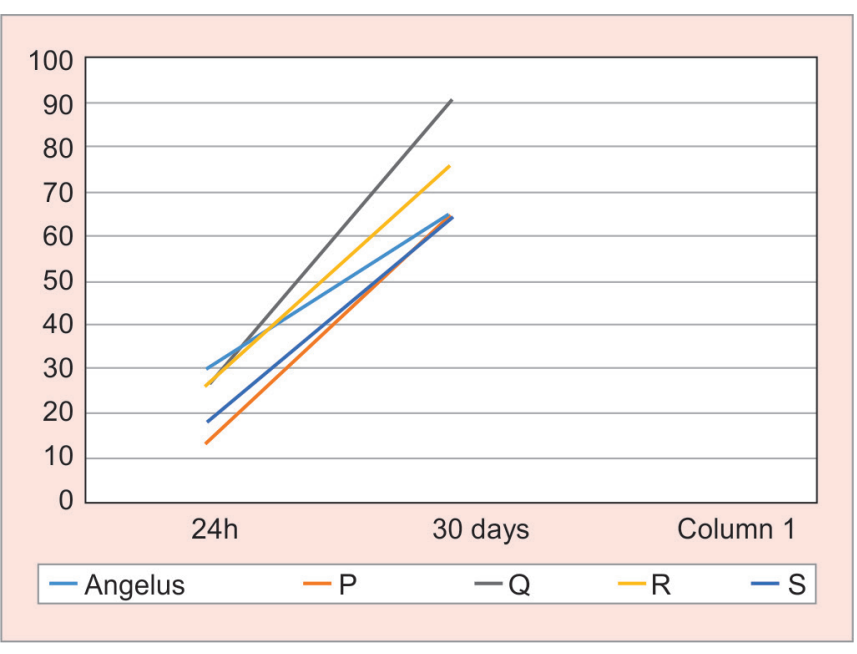

Graph 2: Effecting pattern of time and type of MTAs on compressive strength

As shown in Table 2, average compressive strength in all groups after 30 days has a significant difference with this average over 24 hours, and this difference is statistically significant $(p<0.001)$. In fact, time is a factor influencing the compressive strength.

It is determined, based on Table 2, that the greatest compressive strength after 24 hours is related to the angelus. Group P has the lowest and group Q has the highest compressive strength of Experimental Nanohybrid MTAs. Furthermore, the maximum compressive strength after 30 days is related to MTA of group $Q$, and its minimum amount is related to MTA of group S. The compressive strength of angelus group is also close to the compressive strength of groups S and P (Graphs 1 and 2). The statistical comparison between groups also showed that this difference is significant $(\mathrm{p}<0.001)$. In other words, the type of group also affects the compressive strength.

Pair-wise comparisons of average compressive strength of angelus MTA and four types of experimental MTA after 24 hours are indicated as follows:

- The average compressive strengths of angelus, $R$ and $Q$ MTAs are significantly higher than P and S MTAs $(\mathrm{p}<0.001)$.

- The average compressive strengths of P and S MTAs have no significant difference with each other $(\mathrm{p}>0.05)$.

- The average compressive strengths of angelus, $R$ and Q MTAs have no significant difference with each other $(\mathrm{p}>0.05)$. 
Comparison of Compressive Strength and Setting Time of Four Experimental Nanohybrid MTAs

Table 3: Mean and SD of setting time of commercial MTA (Angelus) and four types of experimental MTAs after 24 hours and 30 days

\begin{tabular}{lllllll}
\hline Time & $N$ & Angelus & $P$ & $Q$ & $R$ & $S$ \\
\hline Initial & 15 & $1549 \pm 8.96^{*}$ & $555 \pm 10.15$ & $1349 \pm 14.49$ & $868 \pm 10.21$ & $1096 \pm 29.98$ \\
& & $25: 49^{* *}$ & $9: 15$ & $22: 29$ & $14: 28$ & $18: 16$ \\
Final & 15 & $2398 \pm 19.78$ & $1046 \pm 8.37$ & $1760 \pm 18.02$ & $1237 \pm 16.83$ & $1523 \pm 44.2$ \\
& & $39: 58$ & $17: 26$ & $29: 20$ & $20: 37$ & $25: 23$ \\
\hline
\end{tabular}

*Second (mean \pm SD); **minute:second; SD: Standard deviation

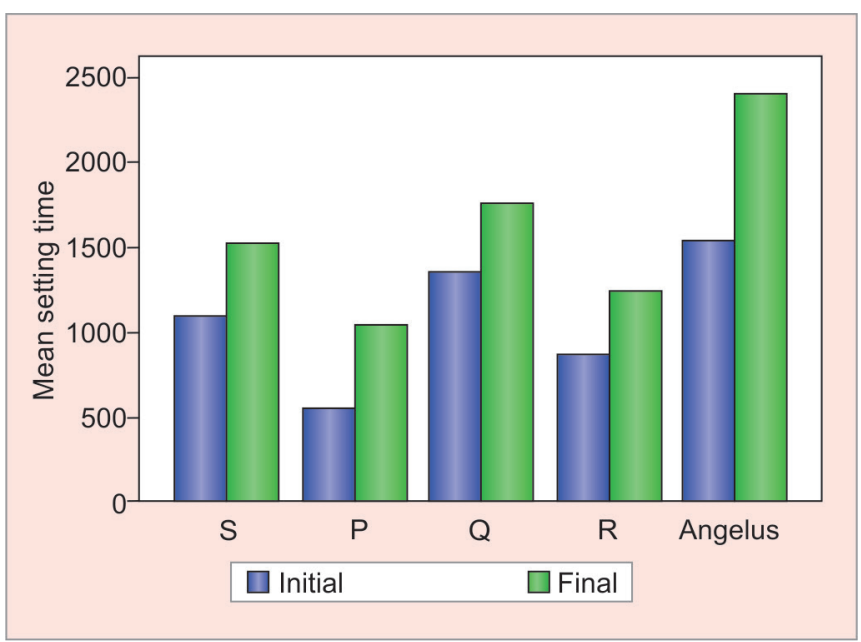

Graph 3: The average setting time of commercial MTAs and four types of experimental MTAs in two studied times

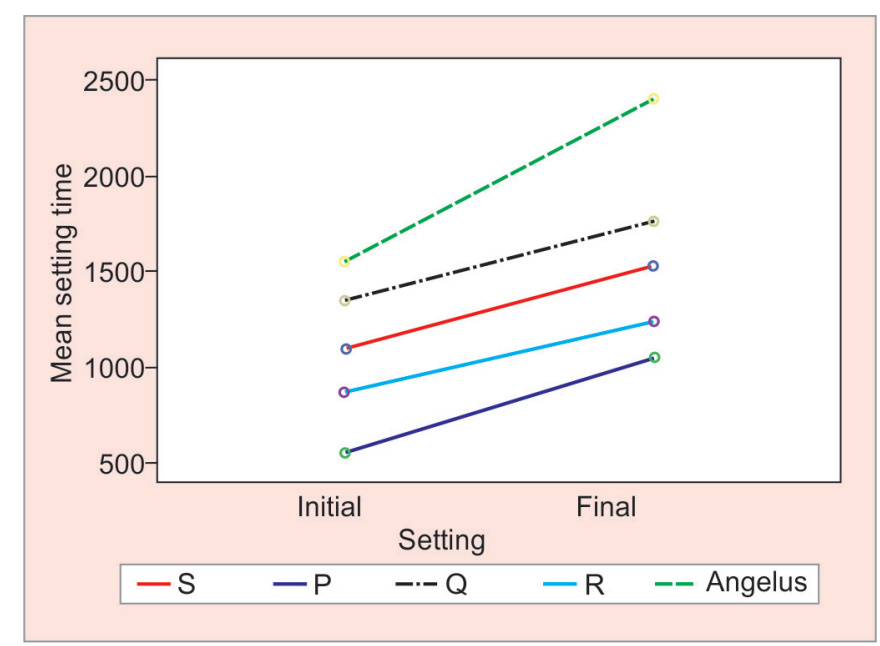

Graph 4: Effecting pattern of time (initial and final) and five groups on setting time
Pair-wise comparisons of average compressive strength of angelus MTA and four types of experimental MTA after 30 days are indicated as follows:

- The average compressive strength of Q MTA is significantly higher than angelus, $\mathrm{R}$ and $\mathrm{P}$ and $\mathrm{S}$ MTAs $(\mathrm{p}<0.001)$.

- The average compressive strengths of angelus, $\mathrm{R}$ and $P$ and S MTAs have no significant difference with each other $(\mathrm{p}>0.05)$.

\section{Findings related to Setting Time}

In the evaluation of setting time, initially all values were converted to seconds to make the analysis easier. In the end, results were again presented in minutes and seconds.

The average setting time, initial and final setting times of commercial MTA, and four types of experimental MTAs are shown in MTA.

Based on the values in Table 3, average initial setting time is less than the final setting time in all groups (Table 3 , Graphs 3 and 4). The results in Table 3 about setting time show that angelus group has the longest setting time. Furthermore, group P has the lowest and group G the longest setting time in experimental groups. The results of the final part are similar to the initial part. Again, the highest rate after angelus is related to group $Q$ and its lowest is related to group P (Graphs 3 and 4). The statistical comparison between groups also showed that this difference is significant $(\mathrm{p}<0.05)$, and, in other words, the type of group affects the setting time. As shown in Table 3, the average setting time has statistically significant difference in all groups in case of final time, compared with the initial time, and this difference is statistically significant $(p<0.05)$. In fact, time is the affective cause in the setting time.

\section{DISCUSSION}

The MTA was primarily introduced as a dental root endfilling material and was widely used in all areas of the root canal. ${ }^{21}$ Mechanical properties, especially compressive strength, are very important in some cases, such as in sealing a massive perforation or immature root apex.

The MTA is mainly a refined Portland cement, which has been formed of calcium and silica with bismuth oxide. ${ }^{21}$ The MTA powder forms a colloidal gel when mixed with water, which is later converted into a hard structure in the presence of moisture. The MTA is a bioactive substance that can create apatite on its surface in the presence of phosphate. ${ }^{22-26}$ In addition, MTA releases components in buffered phosphate saline that starts mineralization. ${ }^{25}$

The combination feature of mixing may be affected by factors, such as the ratio of powder to liquid, mixing method (e.g., the amount of air bubbles trapped in the mix), amount of pressure used to compress humidity, type of MTA, the $\mathrm{pH}$ of environment, type of fluid mixed with the MTA powder, thickness, and temperature. ${ }^{26-29}$ 
In this study, a digital scale was used to make all measurement tools equal. In this way, the weight unit of drops was used, instead of their counting units. Furthermore, based on previous studies, the weight of the liquid removed from the emitters by different people is not the same, and factors, such as the method of removing drops, pressure on the emitter, and the stress level of the practitioner affect the weight of each drop brought out of the emitter. ${ }^{30,31}$ The special spatula, provided by the cement manufacturer, is usually used to take appropriate amounts of powder. The amount of powder taken out by a spatula is not the same in different attempts, not even when one person is using it. The digital scale was used once again in this study to solve this problem. The mixing method was selected based on what was mentioned in articles and scientific references. Samples were prepared by one person to avoid having different tastes in determination of homogeneity of mix, using eyes. The studies showed that MTA has better sealing ability and biocompatibility compared with other dental materials. ${ }^{21}$ In addition, the presence of water does not reduce the sealing ability of MTA..$^{32}$ One of the biggest problems of this material is its long setting time (3-4 hours) ${ }^{21}$ That is why it functions later in clinical terms. Gray MTA cement has a significantly longer initial and final setting time compared with white MTA. ${ }^{33,34}$ Longer setting time of white MTA compared with Portland cement is due to the lower sulfur content and higher calcium aluminate in white MTA. ${ }^{27}$ In several studies, MTA modification has been carried out to shorten the setting time while maintaining its mechanical properties. ${ }^{25}$ Nowadays, adding filler particles to cement to improve its features and reduce setting time has become very common. For example, cement properties have been experimentally evaluated by adding nanoparticles. ${ }^{19}$

In general, amorphous or glass silica reacts with calcium hydroxide to form hydrated calcium silicate. Pozzolanic reaction is a chemical reaction that occurs in Portland cement, being, in fact, a simple acid-based reaction and is the reaction between calcium hydroxide (which is also called portlandite) and silicic acid $\left(\mathrm{H}_{4} \mathrm{SiO}_{4}\right.$, or $\left.\mathrm{Si}(\mathrm{OH})_{4}\right)$.

A lot of cements also have aluminate, which reacts with calcium hydroxide and water and forms hydrated calcium aluminate containing $\mathrm{C}_{4} \mathrm{AH}_{13}$ and $\mathrm{C}_{3} \mathrm{AH}_{6}$. The $\mathrm{Al}_{2} \mathrm{O}_{3}$ leads to immediate setting of cement. Gypsum $\left(\mathrm{CaSO}_{4} \cdot 2 \mathrm{H}_{2} \mathrm{O}\right)$ is added to the cement to prevent this. ${ }^{35}$

The amount of this reaction in time is proportional to the amount of available reactants; thus, using nanoparticles to increase the level of response seems like a good idea. Studies have shown that nanoparticles not only act as fillers to improve microstructures but also act as activators to start the reaction and accelerator of hydration.
In addition, the continued progress of hydration over time was observed in these studies in electron micrograph scanning. ${ }^{36}$

It seems that the acceleration in the process of hydration has affected the improvement of the physical properties of cement. Black et $\mathrm{al}^{37}$ demonstrated that $\mathrm{Ca}_{3} \mathrm{Al}_{2} \mathrm{O}_{6}$ increases hydration process and compressive strength. Most of the researchers support the idea that adding a small amount of nanoparticles to Portland cement increases the resistance to pressure, especially in the early stages.

Compressive strength testing is mainly used in industry for the evaluation of cement. In our study, compressive strength may be influenced by factors, such as conditions of mixing. However, these factors have similar effects on all groups and will not change the results.

Cement setting time has great clinical importance similar to other restorative materials because convenient features of materials are obtained after setting time. Based on EN 196-3 standard (2005), a minimum amount of water must be used for mixing with powder. In the meantime, water must be enough to an extent to make full hydration to occur.

In 2007, Ber et al ${ }^{13}$ proposed $10 \times 2 \mathrm{~mm}$ generators, and since then, measuring standards for setting time have been set based on these dimensions. ${ }^{38}$ In this study, weights of 113.4 and $456.5 \mathrm{gm}$ were used for initial and final setting times, similar to many studies of the Gilmore needle.

So far, many efforts have been made to reduce the setting time, such as the addition of calcium chloride, polymer, and plasticizer. ${ }^{39,40}$ The initial and final setting times of Brazilian angelus MTA cement have been claimed by the manufacturer to be 10 to 15 minutes. Under standard conditions of research, the results of the present study are not in line with the manufacturer's claim. The present study indicates a significant difference with the manufacturer's claim. The results of our study were less than that of the study of Kogan et $\mathrm{al}^{41}{ }^{41}$ which had differences in the testing method: That study used the Vicat method and indent has been done at intervals of 5 minutes, but the Gilmore needles, with 30-second intervals, have been used in our study. The results of our study are in line with the results of Chiang and Ding's study. ${ }^{42}$ They reported times of 25:49 and 39:58 minutes.

Adding nanoparticles of alumina oxide to nanoparticles of titanium oxide significantly reduces the setting time. This difference can be related to higher surface area of the group containing surface area because it leads to faster reaction of the powder with the liquid. The results of the present study are in line with the study of Saghiri et $\mathrm{al}^{43}$, with the difference that a different element has been used in that study to produce nano white MTA. The 
lowest time setting was related to group $\mathrm{P}$, which is in line with what was said about setting reaction because $P$ material has alumina, but lacks gypsum. The compressive strength of dental materials is among the factors that are important in loading during function. Studies on the MTA believe that this matter will be placed indirectly under load. $^{2}$

Based on the results of this study, compressive strength has had a significant increase from 24 hours to 30 days in all groups. According to Islam et al, ${ }^{33}$ this is due to the continuous setting of material, which leads to increased strength and stability.

A 24-hour compressive strength of angelus MTA in this study is consistent with the study of Kogan et al. ${ }^{41}$ The 24-hour and 30-day compressive strengths of angelus MTA in the study are not consistent with the studies of Chung et $\mathrm{l}^{44}$ and Tanomaru-Filho et $a{ }^{45}$ In the study of Chung et al, ${ }^{44}$ MTA compressive strength in 24 hours has been reported to be about $18 \mathrm{MPa}$, which is much lower compared with the number reported in our study (30 $\mathrm{MPa})$. There are differences in the test method: plastic generators with a diameter of $4 \mathrm{~mm}$ and a height of 8 $\mathrm{mm}$ each have been used in that study. The samples have remained in the generator for 24 hours, while stainless steel generators, with a height of $6 \mathrm{~mm}$, have been used in our study, and samples have been taken out of the generator.

In the study of Tanomaru-Filho et al, ${ }^{45}$ 24-hour and 21-day strengths are roughly half the amount reported in our study. There were differences in the method of experiments with this study. Samples prepared from each cement had $12 \mathrm{~mm}$ height and $6 \mathrm{~mm}$ diameter. However, in the present evaluation, each sample had $6 \mathrm{~mm}$ height and $4 \mathrm{~mm}$ diameter. This difference can be attributed to the operator mixing techniques. ${ }^{46}$

Based on the results of this study, the experimental MTA groups had lower compressive strength compared with angelus MTA in 24 hours. This can be due to strong reactions between cement matrix particles and nanoparticles. Group P has the minimum amount of strength significantly, which is probably due to the agglomeration of nanoparticles in high percentages, which acts in the form of weaknesses and increases the brittleness of the material. It should be noted that the initial and final resistances of the material are independent of each other. If the reaction proceeds through hydrolysis instead of hydration, differences in the initial and 1-month compressive strengths of this group can be justified to some extent. Group Q showed the highest compressive strength in 30 days. In general, the 30-day compressive strengths of groups $\mathrm{R}$ and $\mathrm{Q}$ were greater than commercial MTA. This result is different from the result of compressive strength in 24 hours. The explanation is possible in this manner: nano particles' agglomeration acts as weaknesses in 24 hours, but on the contrary, it leads to continued hydration over time. Group $Q$ has a smaller percentage of nanoparticles compared with other groups, and hence, it has a lower agglomeration level and shows a higher strength compared with other groups.

\section{CONCLUSION}

- Experimental MTA groups showed appropriate properties in setting time, which can be compared with angelus MTA group.

- Nano-oxide particles have significantly reduced the initial and final setting times.

- Setting time claimed by the angelus MTA manufacturer is less than the results of this study.

- Compressive strength of experimental group Q in 30 days was reported to be significantly higher than those of other groups.

\section{REFERENCES}

1. Sonarkar S, Purba R. Bioactive materials in conservative dentistry. Int J Contemp Dent Med Rev 2015 Feb;2015:340115.

2. Chakraborty A. Will Portland cement be a cheaper alternative to mineral trioxide aggregate in clinical use? A comprehensive review of literature. Int J Contemp Dent Med Rev 2015 Apr;2015:110215.

3. Shabahang S, Torabinejad M. Treatment of teeth with open apices using mineral trioxide aggregate. Pract Periodontics Aesthetic Dent 2000 Apr;12(3):315-320.

4. Holland R, de Souza V, Murata SS, Nery MJ, Bernabé PF, Otoboni Filho JA, Dezan Júnior E. Healing process of dog dental pulp after pulpotomy and pulp covering with mineral trioxide aggregate or Portland cement. Braz Dent J 2001 Jul;12(2):109-113.

5. Eidelman E, Holan G, Fuks AB. Mineral trioxide aggregate versus formocresol in pulpotomized primary molars: a preliminary report. Paediatr Dent 2001 Jan-Feb;23(1):15-18.

6. O'Sullivan SM, Hartwell GR. Obturation of a retained primary mandibular second molar using mineral trioxide aggregate: a case report. J Endod 2001 Nov;27(11):703-705.

7. Hayashi M, Shimizu A, Ebisu S. MTA for obturation of mandibular central incisors with open apices: case report. J Endod 2004 Feb;30(2):120-122.

8. Vizgirda PJ, Liewehr FR, Patton WR, McPherson JC, Buxton TB. A comparison of laterally condensed gutta-percha, thermosplasticized gutta-percha and mineral trioxide aggregate as root canal filling materials. J Endod 2004 Feb;30(2):103-106.

9. Witherspoon DE, Ham K. One-visit apexification: technique for inducing root-end barrier formation in apical closures. Pract Proced Aesthet Dent 2001 Aug;13(6):455-460.

10. Holland R, de Souza V, Nery MJ, Otoboni Filho JA, Bernabé PF, Dezan Júnior E. Reaction of dog's teeth to root canal filling with mineral trioxide aggregate or a glass ionomer sealer. J Endod 1999 Nov;25(11):728-730.

11. Torabinejad M, Chivian N. Clinical applications of mineral trioxide aggregate. J Endod 1999 Mar;25(3):197-205.

12. Torabinejad M, Hong CU, McDonald F, Pitt Ford TR. Physical and chemical properties of a new root-end filling material. J Endod 1995 Jul;21(7):349-353. 
13. Ber BS, Hatton JF, Stewart GP. Chemical modification of ProRoot MTA to improve handling characteristics and decrease setting time. J Endod 2007 Oct;33(10):1231-1234.

14. Gartner AH, Dorn SO. Advances in endodontic surgery. Dent Clin North Am 1992 Apr;36(2):357-378.

15. Parirokh M, Asgary S, Eghbal MJ, Stowe S, Eslami B, Eskandarizade A, Shabahang S. A comparative study of white and grey mineral trioxide aggregate as pulp capping agents in dog's teeth. Dent Traumatol 2005 Jun;21(3):150-154.

16. Matt GD, Thorpe JR, Strother JM, McClanahan SB. Comparative study of white and gray mineral trioxide aggregate (MTA) simulating a one- or two-step apical barrier technique. J Endod 2004 Dec;30(12):876-879.

17. Li H, Xiao HG, Yuan J, Ou JP. Microstructure of cement mortar with nano-particles. Composites 2004 Mar;35:185-189.

18. Ji T. Preliminary study on the water permeability and microstructure of concrete incorporating nano- $\mathrm{SiO}_{2}$. Cem Concr Res 2005 Jul;35:1943-1947.

19. Jo BW, Kim CH, Tae GH, Park JB. Characteristics of cement with nano $\mathrm{SiO}_{2}$ particles. Constr Build Mater 2007 Jul;21(6):1351-1355.

20. Lee JB, Park SJ, Kim HH, Kwon YS, Lee KW, Min KS. Physical properties and biological/odontogenic effects of an experimentally developed fast-setting a-tricalcium phosphate-based pulp capping material. BMC Oral Health 2014 Jul;14(1):87.

21. Torabinejad M, Parirokh M. Mineral trioxide aggregate: a comprehensive literature review-Part II: leakage and biocompatibility investigations. J Endod 2010 Feb;36(2):190-202.

22. Gandolfi MG, Iacono F, Agee K, Siboni F, Tay F, Pashley DH, Prati C. Setting time and expansion in different soaking media of experimental accelerated calcium-silicate cements and ProRoot MTA. Oral Surg Oral Med Oral Pathol Oral Radiol Endod 2009 Dec;108(6):e39-e45.

23. Khandelwal A, Karthik J, Nadig RR, Jain A. Sealing ability of mineral trioxide aggregate and bio-dentine as root end filling material, using two different retro preparation techniques-an in vitro study. Int J Contemp Dent Med Rev 2015 Feb;2015:150115.

24. Gandolfi MG, Taddei P, Tinti A, Prati C. Apatite-forming ability (bioactivity) of ProRoot MTA. Int Endod J 2010 Oct;43(10): 917-929.

25. Hwang YC, Kim DH, Hwang IN, Song SJ, Park YJ, Koh JT, Son $\mathrm{HH}$, Oh WM. Chemical constitution, physical properties, and biocompatibility of experimentally manufactured Portland cement. J Endod 2011 Jan;37(1):58-62.

26. Lee YL, Lee BS, Lin FH, Yun Lin A, Lan WH, Lin CP. Effects of physiological environments on the hydration behavior of mineral trioxide aggregate. Biomaterials 2004 Feb;25(5): 787-793.

27. Dammaschke T, Gerth HU, Züchner H, Schäfer E. Chemical and physical surface and bulk material characterization of white ProRoot MTA and two Portland cements. Dent Mater 2005 Aug;21(8):731-738.

28. Danesh G, Dammaschke T, Gerth HU,Zandbiglari T, Schäfer E. A comparative study of selected properties of ProRoot mineral trioxide aggregate and two Portland cements. Int Endod J 2006 Mar;39(3):213-219.

29. Alhadainy HA, Himel VT. Evaluation of the sealing ability of amalgam, Cavit, and glass ionomer cement in the repair of furcation perforations. Oral Surg Oral Med Oral Pathol 1993 Mar;75(3):362-366.

30. Mount, GJ. An atlas of glass-ionomer cements: a clinician's guide. Brecon: CRC Press; 2003.

31. McLean JW, Wilson AD. The clinical development of the glass-ionomer cements. i. Formulations and properties. Aust Dent J 1977 Feb;22(1):31-36.

32. PelliccioniGA, Vellani CP, Gatto MR, GandolfiMG, MarchettiC, Prati C. Proroot mineral trioxide aggregate cement used as a retrograde filling without addition of water: an in vitro evaluation of its microleakage. J Endod 2007 Sep;33(9):1082-1085.

33. Islam I, Chng HK, Yap AU. Comparison of the physical and mechanical properties of MTA and Portland cement. J Endod 2006 Mar;32(3):193-197.

34. Storm B, Eichmiller FC, Tordik PA, Goodell GG. Setting expansion of gray and white mineral trioxide aggregate and Portland cement. J Endod 2008 Jan;34(1):80-82.

35. Akbari M, Zebarjad SM, Nategh B, Rouhani A. Effect of nano Silica on setting time and physical properties of mineral trioxide aggregate. J Endod 2013 Nov;39(11):1448-1451.

36. Björnström J, Martinelli A, Matic A, Börjesson L, Panas I. Accelerating effects of colloidal nan-Silica for beneficial calcium-silicate-hydrate formation in cement. Chem Phys Lett 2004 Jul;392(1):242-248.

37. Black L, Breen C, Yarwood J, Deng CS, Phipps J, Maitland G. Hydration of tricalcium aluminate $\left(\mathrm{C}_{3} \mathrm{~A}\right)$ in the presence and absence of gypsum studied by Raman spectroscopy and X-ray diffraction. J Mater Chem 2006 Jan;16(13):1263-1272.

38. Camilleri J. Modification of mineral trioxide aggregate. Physical and mechanical properties. Int Endod J 2008 Oct;41(10):843-849.

39. BortoluzziEA, BroonNJ, BramanteCM,Garcia RB, deMoraes IG, Bernardineli N. Sealing ability of MTA and radiopaque Portland cement with or without calcium chloride for root-end filling. J Endod 2006 Sep;32(9):897-900.

40. Oliveira IR, Pandolfelli VC, Jacobovitz M. Chemical, physical and mechanical properties of a novel calcium aluminate endodontic cement. Int Endod J 2010 Dec;43(2):1069-1076.

41. Kogan P, He J, Glickman GN, Watanabe I. The effects of various additives on setting properties of MTA. J Endod 2006 Jun;32(6):569-572.

42. Chiang TY, Ding SJ. Comparative physicochemical and biocompatible properties of radiopaque dicalcium silicate cement and mineral trioxide aggregate. J Endod 2010 Oct;36(10): 1683-1687.

43. Saghiri MA, Asgar K, Lotfi M, Garcia-Godoy F. Nanomodification of mineral trioxide aggregate for enhanced physiochemical properties. Int Endod J 2012 Nov;45(11):979-988.

44. Chung H, Kim M, Ko H, Yang W. Evaluation of physical and biologic properties of the mixture of mineral trioxide aggregate and 4-META/MMA-TBB resin. Oral Surg Oral Med Oral Pathol Oral Radiol Endod 2011 Nov;112(5):e6-e11.

45. Tanomaru-Filho M, Morales V, da Silva GF, Bosso R, Reis JM, Duarte MA, Guerreiro-Tanomaru JM. Compressive strength and setting time of MTA and Portland cement associated with different radiopacifying agents. ISRN Dent 2012 Jul; 2012:898051.

46. Attavar SH, Nadig P, Sujatha I. Management of open apex with mineral trioxide aggregate-2 case reports. Int Dent Med J Adv Res 2015 Apr;1:1-4. 